\title{
Serviço Social e escuta especializada: proteção integral ou produção antecipada de provas?
}

\section{Social Service and specialized listening: Full Protection or Early Proof Production?}

\author{
Ana Carolina Galvãoa \\ (1) https://orcid.org/0000-0001-6680-2952 \\ Janaína Barbosa de Morais ${ }^{a}$ \\ (D) https://orcid.org/0000-0003-4633-3946 \\ Nilmar Santos ${ }^{b}$ \\ (1) https://orcid.org/0000-0001-8093-1996
}

Resumo: Problematizar a escuta especializada, aos moldes da Lei no 13.341/2017, de crianças e adolescentes vítimas ou testemunhas de violência, perpassa pela garantia da "proteção integral" frente a reflexão do movimento histórico. 0 presente estudo pretende discutir as implicações de tais requisições nos espaços sócio-ocupacionais do assistente social atuante na Rede de Proteção de Crianças e Adolescentes, a partir de análise bibliográfica e do arcabouço legal acerca da metodologia.

Palavras-chave: Serviço Social. Escuta especializada. Criança e adolescente. Inquirição. Instrumentalidade.

\begin{abstract}
Problematizing the specialized listening, to the molds of the law $13.341 / 2017$, of children and adolescents victims or witnesses of violence, permeated by the guarantee of "integral protection" in the face of the reflection of the historical. The present study intends to discuss the implications of such requests in the sociooccupational spaces of the social worker working in the Child and Adolescent Protection network, based on bibliographic analysis and the legal framework About the methodology.
\end{abstract}

Keywords: Social Work. Specialized Listening. Child and teenager. Inquiry. Instrumentality. 


\section{Introdução}

\section{A} Lei no 13.431, de 4 de abril de 2017, normatiza e organiza em âmbito nacional o Sistema de Garantia de Direitos da Criança e do Adolescente (SGD) no que se refere ao atendimento de vítimas e testemunhas de violência. Elenca ainda as atribuições das diversas políticas públicas que compõem a Rede de Proteção de Crianças e Adolescentes nos termos do artigo 227 da Constituição Federal, do Estatuto da Criança e Adolescente, da Convenção sobre os Direitos da Criança e seus protocolos adicionais, da Resolução no 20/2005 do Conselho Econômico e Social das Nações Unidas e de outros diplomas internacionais. O dispositivo legal define dois tipos de escuta a crianças e adolescentes vítimas e testemunhas de violência: escuta especializada e depoimento especial (Brasil, 2017).

$O$ assistente social, enquanto profissional inserido na divisão social e técnica do trabalho, é demandado a intervir diante das expressões da questão social, conforme a Lei no 8662/93 em distintos espaços sócio-ocupacionais, dentre eles o SGD, onde o profissional do Serviço Social vem atuando na proteção integral ${ }^{1}$ desse público.

Partindo da experiência enquanto técnicas inseridas na Rede de Proteção da Criança e do Adolescente, é possível conjecturar o impacto que tal normativa legal acarretará no fazer profissional do assistente social, o que nos propomos a refletir também neste artigo.

Problematizar o fazer do assistente social na escuta especializada perpassa pelos princípios éticos fundamentais da profissão. Logo, reconhecer a criança e o adolescente enquanto sujeito de direito em situação peculiar de desenvolvimento é reconhecer a liberdade como valor central e tomar a emancipação e a autonomia como direitos humanos fundamentais norteadores da práxis. ${ }^{2}$

1 Compreende-se aqui a proteção integral enquanto reconhecimento da criança e do adolescente como sujeito de direitos, cujos desejos devem ser respeitados durante as intervenções que interferem sobre seu processo de vida, assim como a sua condição peculiar de pessoa em desenvolvimento e seus níveis cognitivos.

2 “[...] uma prática orientada pela teoria, com clareza de finalidade” (Prates, 2012, p. 109). 
Tal escuta, definida na Lei no 3.431/17, estabelece no seu artigo $7^{\circ}$ a entrevista como técnica a ser utilizada pelos profissionais da Rede de Proteção em situações de violências. Determina ainda que tal procedimento seja limitado ao relato do(a) violado(a) para o cumprimento de sua finalidade, entendida aqui como produção probatória conforme o $\S 2^{\circ}$ do artigo 14 . Ao definir o método, a lei limita o caráter teleológico do assistente social e interfere na instrumentalidade a ser aplicada no campo operativo, o que vai na contramão da sua capacidade de análise da realidade e de sua capacitação técnica e política, apontadas pela Lei no 8.662/1993 que caracteriza a atuação do assistente social no atendimento, orientação, identificação e uso de recursos sociais norteados pelos princípios éticos de defesa e ampliação dos direitos sociais. Salienta-se que privativamente o assistente social nas elaborações de instrumentos e produções de documentos direciona sua atuação à matéria, à questão social do Serviço Social.

O presente estudo pretende, através do materialismo histórico-dialético, numa perspectiva dedutiva-indutivo (Prates, 2012), pautar as implicações da escuta especializada nos espaços sócio-ocupacionais dos assistentes sociais atuantes no SGD. Para o alcance de tal pretensão será realizado análise bibliográfica do arcabouço legal acerca da metodologia a partir de um enfoque misto.

A relação entre teoria e prática pode ser apreendida de diversos modos. $\mathrm{O}$ caminho apresentado aqui pressupõe uma relação ontológica. No primeiro momento do texto, pauta-se a metodologia da escuta especializada atrelando-a ao processo histórico de reconhecimento da garantia de direitos fundamentais de crianças e adolescentes. No segundo momento, discute-se o fazer do assistente social na escuta especializada de crianças e adolescentes vítimas ou testemunhas de violências frente às determinações da Lei no 13.341/17. Por fim, as considerações finais problematizam as contradições da metodologia, como apresentada na normativa legal, frente a instrumentalidade, as competências e atribuições estabelecidas na Lei de Regulamentação da Profissão do Assistente Social. 
Embora a definição da escuta especializada tenha aspectos singulares para a proteção integral de crianças e adolescentes, é representativa de preocupações de um segmento do debate profissional do Serviço Social, visto que aparece como uma lacuna de pesquisa em textos que problematizam a referida legislação.

Assim, torna-se relevante tal discussão diante do processo de investigação social, que tem como característica analisar a realidade historicamente construída enquanto estratégia e mobilização para os enfrentamentos e a transformação social.

\section{Escuta especializada: da proteção integral de crianças e adolescentes à produção antecipada de prova}

As relações de poder estabelecidas nas diversas esferas da sociedade favorecem a prática de violências contra crianças e adolescentes por negar-lhes a liberdade, a dignidade, o respeito e a oportunidade de crescer em condições humanas saudáveis.

Na década de 1990 ascende a preocupação internacional em assegurar os direitos de crianças e adolescentes. No ano de 1924, a Convenção de Genebra pauta a importância de se debater os direitos da infância entre as nações. No Brasil, propagaram-se, principalmente no circuito dos legisladores federais, debates a respeito da assistência e da forma de proteção à infância e adolescência.

Na década de 1980, o Brasil vivenciou profundas transformações sociais e políticas. Os movimentos organizados da sociedade civil ganharam espaço frente ao processo de redemocratização do país, tendo participação direta na construção da Constituição de 1988. Além dos princípios democráticos gerais, a Carta Magna trouxe premissas importantes aos direitos de crianças e adolescentes.

Art. 227 - É dever da família, da sociedade e do Estado, assegurar à criança e ao adolescente, com absoluta prioridade, o direito à vida, à 
saúde, à alimentação, à educação, ao lazer, à profissionalização, à cultura, à dignidade, ao respeito, à liberdade, à convivência família e comunitária, além de colocá-los a salvo de toda forma de negligência, discriminação, exploração, violência, crueldade e opressão. (Brasil, 2008b, p. 145)

A proteção integral estabelece com absoluta prioridade os direitos fundamentais para o pleno desenvolvimento de crianças e adolescentes. Sobre esse princípio, Cury (2008) afirma que seu entendimento perpassa pelo conjunto de direitos que são próprios dos sujeitos em condição peculiar de desenvolvimento, o que coloca crianças e adolescentes como titulares de direitos, rompendo com a ideia de simples objetos de intervenção do mundo adulto.

Ainda hoje crianças e adolescentes são alvo de uma violência social exposta na falta de projetos de vida. Apesar dos avanços no campo da institucionalidade, presencia-se a expressa necessidade da eficácia na implementação das normativas legais, da obtenção de recursos para orçamento público e da implementação de políticas públicas para a infância e adolescência, o que, segundo Iamamoto (2009), perpassa por uma tendência de fragmentação dos usuários demandantes da ação do Estado, via políticas públicas, segundo características de geração, de gênero e étnico-culturais.

Torna-se então fundamental revisar o que está posto, retomar e aperfeiçoar os direcionamentos que apontam para uma prática intersetorial do SGD. É preciso analisar as respostas dadas pelo Estado às violações de direitos de crianças e adolescentes, expressões das desigualdades sociais, para assim não responsabilizar vítimas e famílias por uma violência estrutural inerente ao movimento histórico do sistema capitalista, expressa também na adoção da mudança comportamental e de hábitos como via de atendimento a famílias (Mioto; Campos; Carloto, 2015).

A alteração de paradigmas que se requer não se insere numa tarefa simples, visto tais conceitos estarem arraigados de acordo com os dogmas dominantes da sociedade. Nesse sentido, vêm se instaurando mecanismos democráticos formais visando seu enfrentamento. 
A institucionalização da Lei n. 13.431/2017 normatiza o atendimento de crianças e adolescentes vítimas e testemunhas de violência, definindo dois tipos de escuta a serem adotados a partir de sua vigência. Indica a necessidade da cooperação e articulação no atendimento da Rede de Proteção, a fim de garantir sua agilidade, devendo os órgãos públicos de atendimento adotar procedimentos para a revelação espontânea da violência visando a preservação das informações colhidas.

A materialização da proteção integral perpassa pelo enfrentamento das práticas menoristas e de tutela ${ }^{3}$ que ainda se fazem presente no cotidiano da Rede de Promoção e Proteção. Normatizar procedimentos de escuta e inquirição é relegar a compreensão de criança e adolescente sujeito de direito em desenvolvimento ao processo de produção antecipada de prova.

\subsection{Escuta de crianças e adolescentes em situação de violência}

No decorrer do processo histórico, as ações de enfrentamento das violações de direitos de crianças e adolescentes ficaram centralizadas nos serviços e programas da política da Assistência Social. Com advento do Sistema Único de Assistência Social (Suas), instituem-se os níveis de proteção social, e as ações dos referidos programas são reordenadas para o Centro de Referência Especializado de Assistência Social (Creas).

Em 2006, o Conselho Nacional de Direitos da Criança e do Adolescente (Conanda) deliberou a Resolução no 113, atualizada pela Resolução no 117 desse mesmo ano, que dispõe sobre os parâmetros para institucionalização e fortalecimento do SGD, implementando a articulação e a integração das instâncias públicas governamentais e da sociedade civil na aplicação da promoção, defesa e controle para efetivação dos direitos humanos de crianças e adolescentes.

3 Responsabilização e culpabilização da criança e do adolescente por sua condição social e econômica. 
Como estratégia do órgão do eixo de defesa - que objetiva o acesso à Justiça, à proteção legal dos direitos de crianças e adolescentes, assegurando a exigibilidade e a impositividade, além da responsabilização dos direitos violados e de possíveis violadores (Conanda, 2006) -, vem-se utilizando desde 2003 a escuta de crianças e adolescentes no processo de responsabilização dos possíveis violadores.

Tal experiência partiu do Poder Judiciário do Rio Grande do Sul. A partir da Recomendação no 33 de 2010, o Conselho Nacional de Justiça orientou que se estabelecesse a estruturação dos espaços destinados à aplicação dessa metodologia, intitulado na época Depoimento Sem Danos, ${ }^{4}$ em todo o país. Apesar de tal determinação para aplicação da metodologia, ainda não se tem um consenso sobre sua aplicabilidade frente aos operadores de direitos e profissionais da Rede de Promoção e Proteção (CFESS, 2018).

A Lei no 13.431/17 vem institucionalizar a escuta especializada, objetivando a normatização e a organização do atendimento a crianças e adolescentes vítimas e testemunhas de violências, criando mecanismos para prevenir e coibir violações contra esse segmento. Traz a garantia dos direitos fundamentais como norte. Ao tipificar as violências contra crianças e adolescentes no artigo $4^{\circ}$, estabelece: "Art. $4^{\circ}$, IV, $\S 1^{\circ}-$ Para efeitos dessa Lei, a criança e o adolescente serão ouvidos sobre a situação de violência por meio de escuta especializada e depoimento especial" (Brasil, 2017).

Caracteriza a escuta especializada no artigo $7^{\circ}$ como "procedimento de entrevista sobre situação de violência com criança ou adolescente perante o órgão da Rede de Proteção, limitado o relato estritamente ao necessário para o cumprimento de tal finalidade". No artigo $8^{\circ}$ tipifica o depoimento especial como "procedimento de oitiva de criança ou adolescente vítima ou testemunha de violência perante autoridade policial

4 O depoimento especial, cuja metodologia foi inicialmente apresentada no debate com a denominação de Depoimento sem Danos através do Projeto de Lei n. 3.792/2014 da deputada federal Maria do Rosário (CFESS, 2018) aprovado em abril de 2017. 
ou judicial". A redação da lei traz ainda que tais metodologias devem ser aplicadas em local apropriado e acolhedor, com infraestrutura e espaço físico que garantam a privacidade da criança ou do adolescente.

Ainda no artigo $4^{\circ}$, inciso $4^{\circ}$, os parágrafos $2^{\circ}$ e $3^{\circ}$ estabelecem respectivamente que "os órgãos de saúde, assistência social, educação, segurança pública e justiça adotarão os procedimentos necessários por ocasião da revelação espontânea da violência" e, "na hipótese de revelação espontânea da violência, a criança e o adolescente serão chamados a confirmar os fatos na forma específica no $\S 1^{\circ}$, já citado aqui, salvo em caso de intervenção de saúde".

Contudo, o que se presencia no cenário atual no Poder Judiciário, instituições do eixo de defesa do SGD, é a ausência de equipes interdisciplinares especializadas e efetivadas. Em virtude dessa ausência de estruturação nas instâncias investigativas e de responsabilização, atrelada à necessidade de garantir celeridade aos processos judiciais, é que as políticas públicas, de modo geral, vêm sendo requisitadas de forma impositiva, diante de prazos irrisórios justificados pelo rito processual, a suprir as deficiências do quadro de profissionais.

As equipes técnicas são intimadas a elaborar estudos, averiguações, localização e fornecimentos de dados dos litigantes e até mesmo apuração dos fatos. Tal vertente é, também, uma das faces do processo de judicialização das ações do Poder Executivo para além da discussão existente no âmbito da garantia do acesso aos serviços do cidadão.

Dada nossa experiência de atuação profissional e a participação em momentos de formação e organização, presenciamos relatos de profissionais inseridos nas unidades de atendimento das políticas públicas que são cotidianamente requisitados a realizar oitivas e fornecer dados referentes aos atendimentos realizados, sobretudo profissionais da área da Assistência Social e da Saúde, ${ }^{5}$ a fim de subsidiarem as peças de investigação policial e processos de responsabilização criminal de agressores.

5 Embora não exista subsídios de sistematização na área da saúde, tal demanda é apresentada nas falas dos profissionais no âmbito do SGD. 
Em 2014, a partir de requisições dos profissionais do país, o Conselho Federal de Serviço Social (CFESS) enviou pedido de providências ao Conselho Nacional de Justiça, pondo em evidência as demandas que chegam aos espaços sócio-ocupacionais dos assistentes sociais, advindas do Poder Judiciário, Segurança Pública e Conselhos Tutelares (CFESS, 2014a).

Tais requisições vêm sendo historicamente questionadas pelos profissionais da Rede de Promoção e Proteção de Crianças e Adolescentes. O CFESS, assim como conselhos de outras categorias, posiciona-se através da elaboração de pareceres jurídicos, normativas e notas técnicas (CFESS, 2018).

Apesar de tais questionamentos e posicionamentos, são demandados dos profissionais da Rede de Proteção da Criança e do Adolescente meios que viabilizem a responsabilização das violações e dos possíveis violadores. As solicitações aos assistentes sociais vão além dos pareceres e estudos sobre as condições sociais de crianças e adolescentes em seu contexto sócio-histórico para apreensão dos processos que atravessam a violência e a negligência vivenciadas. Tais requisições se contrapõem ao papel da garantia da proteção integral de crianças e adolescentes, respeitando a especificidade enquanto política pública que preconiza o SGD.

\section{O fazer profissional do assistente social na escuta especializada de crianças e adolescentes}

\subsection{Rede de Proteção de Crianças e Adolescentes enquanto espaço sócio-ocupacional do assistente social}

O Serviço Social, ${ }^{6}$ como especialização do trabalho coletivo, apresenta competências e atribuições construídas em consonância com o

6 Partimos da concepção de Serviço Social de Iamamoto. A autora compreende a profissão como "especialização do trabalho da sociedade, inscrita na divisão social e técnica do trabalho social” (2009, p. 23). Profissional que atua nas expressões da questão social, precisamente "tal 
projeto ético-político da profissão que reconhece "a liberdade como valor ético central e direciona-se a defesa intransigente dos direitos humanos e recusa do arbítrio e do autoritarismo" (CFESS, 2012). Possui características específicas à sua "práxis", que o difere das demais profissões. Atua nas expressões da questão social orientado pela teoria social crítica e por valores humano genéricos expressos em legislações regulatórias.

Reconhece a questão social como resultante das contradições das relações sociais da sociedade capitalista, cujas expressões modificam-se e apresentam-se no cotidiano profissional cada vez mais aprofundadas como requisiç̧̃es advindas da classe trabalhadora. Assim, desvendar os movimentos históricos presentes no direcionamento dessas requisições é parte constitutiva da profissão, inserida na instrumentalidade do Serviço Social, como indica Guerra (2000, p. 1):

A instrumentalidade no exercício profissional refere-se, não ao conjunto de instrumentos e técnicas (neste caso, a instrumentação técnica), mas uma determinada capacidade ou propriedade constitutiva da profissão, construída e reconstruída no processo sócio-histórico.

Na Rede de Proteção, o assistente social tem sua atuação direcionada para contemplar aspectos atinentes aos direitos fundamentais de crianças e adolescentes, à proteção integral e ao reconhecimento desses como sujeitos de direitos que demandam atenção a sua condição peculiar de desenvolvimento.

Nesse sentido, as normatizações do SGD perpassam pelo movimento histórico das políticas públicas pelo Estado e sua organização. No Brasil, a década de 1990, embora marcada por profundas transformações advindas do processo de redemocratização, sofre influências neoliberais,

como se expressam na vida dos indivíduos sociais de distintos segmentos das classes subalterna" (Iamamoto, 2009, p. 19). Desvenda necessariamente nesse processo as relações sociais capitalistas e tensões históricas entre os espaços das políticas públicas, que assume ainda o compromisso com a classe trabalhadora e com a afirmação dos direitos sociais, da liberdade como valor ético central e a emancipação humana. 
intensificadas com a crise do capital, que alteram as condições de trabalho do assistente social, conforme explicitado em documento da Abess (1997, p. 60-61):

O trabalho do Assistente Social é, também, afetado por tais transformações, produto das mudanças na esfera da divisão sociotécnica do trabalho, no cenário mundial. Os pressupostos norteadores da concepção de formação profissional, que informa a presente revisão curricular, são os seguintes: [...] O agravamento da questão social em face das particularidades do processo de reestruturação produtiva no Brasil, nos marcos da ideologia neoliberal, determina uma inflexão no campo profissional do Serviço Social. Esta inflexão é resultante de novas requisições postas pelo reordenamento do capital e do trabalho, pela reforma do Estado e pelo movimento de organização das classes trabalhadoras, com amplas repercussões no mercado profissional de trabalho. $O$ processo de trabalho do Serviço Social é determinado pelas configurações estruturais e conjunturais da questão social e pelas formas históricas de seu enfrentamento, permeadas pela ação dos trabalhadores, do capital e do Estado, através das políticas e lutas sociais.

A perspectiva neoliberal, por seu agnosticismo, não reconhece a existência de uma essência dialética histórica. Tal direcionamento reduz a práxis a processos engessados que desconsidera a intencionalidade dos sujeitos, por conseguinte, seu processo de trabalho. As políticas públicas e sociais, conforme Guerra (2014), configuram-se enquanto estratégias de enfrentamento das crises do capital e servem ao Estado para garantir sua legitimidade perante as duas classes fundamentais: trabalhadores e capitalistas. Enquanto estratégias do Estado, promovem o consenso e mantêm a força de trabalho, escondendo a contradição de que são resultados de luta e conquista dos trabalhadores.

$O$ assistente social, ao atuar na intermediação entre as demandas do trabalhador e o acesso deles a serviços e programas sociais, coloca-se na linha de intersecção das esferas pública e privada, o que exige do profissional reconhecer as dimensões presentes na prática do Serviço Social: ético-política, teórico-metodológica e técnico-operativa. 
Tais dimensões possuem uma unidade de natureza teórica e prática. Para Mota (2003), enquanto a dimensão política da prática encontra-se imbricada nos objetivos e finalidades das ações, a dimensão ética reclama por valores e princípios humanos, políticos e civilizatórios, e a dimensão prático-operativa consiste na capacidade de articular os meios disponíveis e os instrumentos de trabalho com base nos valores. Se é a dimensão prático-operativa que impõe a capacidade de articular meios para executar o trabalho, ocorre que o que temos disponível são essas legislações que, podemos alegar, não foram construídas por profissionais da área que lidam com as demandas e, mais ainda, não atendem aos critérios e às requisições do processo de trabalho do assistente social.

A partir dessa compreensão, busca-se problematizar a atuação do assistente social na escuta especializada partindo de uma abordagem ontológica que considere desde a inserção da profissão na divisão social e técnica do trabalho a sua demanda por respostas concretas que modifiquem o contexto. Daí a necessidade de apreender o modelo, as determinações e configurações históricas da Rede de Proteção, posto que ela constitui um espaço sócio-ocupacional dos assistentes sociais.

\subsection{O fazer profissional do assistente social na escuta especializada de crianças e adolescentes: agente de proteção ou inquiridor?}

As atribuições e competências dos assistentes sociais, regulamentadas através da Lei $n^{\circ}$ 8662/1993, os habilitam à prestação de serviços em matéria, área e unidades do Serviço Social. Suas ações apresentam o caráter socioeducativo, como pontua Iamamoto (2009), que dialoga com os princípios éticos profissionais direcionados a liberdade, autonomia e emancipação humana, a democracia, a ampliação dos direitos sociais, a articulação com a luta geral dos trabalhadores e com a qualidade dos serviços prestados à população. 
Na práxis do assistente social no atendimento a crianças e adolescentes, sobretudo em situações de violações de direitos, é imprescindível compreender e identificar as demandas institucionais, sociais e profissionais a fim de não cair em armadilhas de vincular a sua atuação a requisições institucionais, ou mesmo da política pública estatal, marcadas por orientações focalizadoras e reducionistas que não compreendem as expressões da questão social incidentes na condição de vida dos usuários, e por ações/omissões do Estado na mediação das demandas da classe trabalhadora e os direitos sociais.

Utilizando-se da dimensão teórico-metodológica ao ser requisitado a atuar frente a demandas de crianças e adolescentes vítimas ou testemunhas de violência, o assistente social volta a sua prática para busca da compreensão do contexto histórico, econômico, familiar, comunitário, cultural/étnico e político, configurando os elementos estruturantes/determinantes das análises que operação ao identificar o terreno onde se, que expressam as violações de direitos.

As estratégias e técnicas a serem utilizadas, assim como indica Guerra (2014, p. 34), "se revestem de uma intencionalidade profissional", sendo estas determinadas pela realidade identificada. Os instrumentais não encontram seus fins em si mesmo.

A escuta especializada aos moldes da Lei $n^{\circ} 13.431 / 17$, objeto que tratamos neste artigo, apresenta a tendência de aprisionar o profissional em sua racionalidade formal-abstrata, ${ }^{7}$ visto que não considera as especificidades das profissões inscritas na divisão social e técnica do trabalho.

\footnotetext{
Por operar em nível imediato e pragmático, a racionalidade formal-abstrata inerente à sociedade burguesa ancora suas análises na aparência dos fenômenos sociais. Deste modo, suas conclusões e respostas são superficiais, pois não consideram a gênese. O Serviço Social, como profissão eminentemente interventiva e inserida nesse processo histórico, é também requisitado a pautar sua atuação na perspectiva formal para atender as exigências institucionais. Contudo, é a partir do amadurecimento teórico da profissão sobre sua prática e da aproximação com teorias macroscópica que a estrutura, a conjuntura e os contextos nos quais a intervenção se realizam passaram a ser preocupação da dimensão teórico-metodológica, assim como o reconhecimento da existência de racionalidades distintas presentes no Serviço Social e do comprometimento com a classe trabalhadora (Guerra, 2014). Nesse contexto, embora se
} 
No cenário brasileiro, intensifica-se o que Iamamoto (2009) aponta como "criminalização da questão social e da luta dos trabalhadores", o que sinaliza a assistencialização das políticas sociais e um aprofundamento de um estado penal. ${ }^{8}$

A tendência de (des)especialização profissional presente nos desenhos das políticas públicas e dos serviços estatais colocam as demandas no campo comum da atuação das várias profissões que compõem as equipes técnicas, conforme analisa Ortiz (2014).

As novas funções delegadas à profissão no trato da demanda postas no campo comum incidem também na dimensão do sigilo, uma vez que as suas rotinas e análises profissionais são postos em instrumentos de registro institucionais. Conforme o Código de Ética do Assistente Social (1993), o profissional tem o dever de guardar o sigilo; este é direcionado à proteção do(a) usuário(a), e mesmo que inserido num contexto multi e interdisciplinar, as informações compartilhadas se darão dentro do "estritamente necessário". A escuta especializada, como tipificada em lei, contrapõe-se à garantia do sigilo profissional na medida em que o registro, tal qual a fala da criança e/ou adolescente, deverá ser compartilhado com instâncias da Rede de Promoção e Proteção.

Refletir sobre o fazer profissional na Rede de Proteção perpassa pela compreensão das condições objetivas e materiais de trabalho ofertadas num contexto de desfinanciamento das políticas públicas.

reconheça a presente influência da racionalidade formal-abstrata, carecemos de ultrapassá-la na intencionalidade de acompanhar a processualidade dos fenômenos sociais, operando assim no campo da racionalidade crítico-dialética, vez que, a razão formal-abstrata, como reflete Guerra (2014) obstaculiza esse processo.

8 Mota (2012), ao discutir as políticas sociais na América Latina, apontam que a partir da década de 1980 as saídas adotadas pelos capitais internacionais defendem a restrição dos direitos trabalhistas e outras conquistas sociais. Tal reconfiguração social, alicerçada na defesa de um mercado como mecanismo de regulação, desvela-se no que Loic Wacquant, analisado por Batista (2012), vai denominar de insegurança social, justificada pelas tensões apresentadas pelas "populações problemáticas". O Estado penal vem regulamentar a punição especialmente dessa população, gerando sua invisibilidade e seu silenciamento, seja pela perspectiva caritativa e de responsabilização de indivíduos, a partir de políticas de atenção a pessoas e famílias em situação de miséria e extrema pobreza, seja pela perspectiva do encarceramento com uma política criminal. 
Ao determinar que crianças e adolescentes em situação ou testemunha de violência serão ouvidas pelas tipificações de escuta e ao indicar que a revelação espontânea será confirmada por tais tipificações, a legislação em voga apresenta contradições quanto à primazia da proteção integral em detrimento da responsabilização das violações e do possível violador, uma vez que leva a priorizar na prática profissional do assistente social a produção de provas antecipadas.

A Lei $n^{\circ}$ 13.341/17 delega ainda aos órgãos de atendimento do SGD a função historicamente exercida pela Segurança Pública e o Ministério Público nos processos de inquérito para investigação da denúncia.

A atuação profissional do assistente social na Rede de Proteção de Criança e Adolescentes atrela-se aos princípios orientadores da medida de proteção, elencadas no artigo 100 do Estatuto da Criança e do Adolescente (ECA), os quais enfatizam o caráter pedagógico da intervenção, priorizando aquelas que visam o fortalecimento dos vínculos familiares e comunitários em detrimento de práticas institucionalizantes, buscando intervir nas condições materiais e sociais a partir da avaliação das ações demandadas ao Estado via implementação de políticas públicas e/ou suas ausências.

Ao determinar a entrevista como técnica a ser utilizada na escuta especializada e ao restringir a técnica ao contexto de violência vivenciada ou presenciada por crianças e adolescentes, a normativa legal aqui apresentada submete a dimensão técnico-operativa do assistente social a uma visão formalista, atrelando a direção da intervenção profissional ao instrumental (Guerra, 2014), como se esse, por si só, fosse capaz de responder à demanda e à requisição profissional. Em nossa análise, tal restrição incumbe o profissional de atividades que fogem às suas atribuições privativas, bem como competências e habilidades profissionais, além de ferir o princípio da isonomia que confere poder às autarquias - conselhos de classe - em legislar e disciplinar sobre o processo de trabalho de suas profissões. Antes, deveria passar por avaliação dos órgãos fiscalizadores das profissões, em especial o CFESS, a disciplina do processo de trabalho que orientaria a intervenção profissional de 
assistentes sociais em demandas que envolvem crianças e adolescentes vítimas ou testemunhas de violências.

O assistente social não está habilitado para mediar situações que mobilizam crianças e adolescentes em sua dimensão psíquica, em face da violência vivenciada. Intervir em tais situações implica atuar em dissonância com suas atribuições e competências, assim como desrespeito e violação à condição peculiar de desenvolvimento desse público. Ferreira, citada por Azambuja (2013, p. 490), ao problematizar a metodologia de inquirição de crianças vítimas de violência sexual, analisa como espaço não violador capaz de proporcionar "a anestesia, para que a criança possa falar no trauma, só se instala num ambiente terapêutico e não avaliativo ou inquiridor".

É preciso atentar para as orientações do CFESS (2014b, p. 22) que afirma que "a dimensão técnico-operativa do Serviço Social não se confunde com imposições do jurídico e do normativo abstrato". O profissional do Serviço Social na Rede de Proteção deve pautar sua atuação norteada pelas atribuições e competências articulados ao projeto ético-político a partir da razão crítico-dialética, tendo clareza dos limites e possibilidades de sua intervenção frente às requisições de escuta a crianças e adolescentes em contexto de violência.

\section{Conclusões}

Trazer à luz as contradições presentes na normatização da escuta especializada no âmbito das políticas públicas que atendem crianças e adolescentes vítimas ou testemunhas de violências é compreender os avanços na garantia dos direitos fundamentais da infância e adolescência enquanto luta histórica, sem perder de vista os desafios para efetivação da proteção integral diante do desmonte do ECA a partir de "uma transição pelo alto", a partir de novos dispositivos legais que o modificam.

9 "Podemos considerar que este processo, tratado por inúmeros atores - a exemplo de Florestan Fernandes - como uma 'transição de alto', deixou a margem das decisões as camadas 
Reconhecer que ainda estamos distantes da efetivação de uma prática de escuta de crianças e adolescentes vítimas e testemunhas de violência que coloque as vozes destes no centro do debate, seus interesses como norteadores das decisões e sua participação de forma horizontalizada e respeitosa incorporada ao fazer dos profissionais da Rede de Proteção é compreender e superar a fictícia oposição entre proteção da autonomia e desenvolvimento.

Por sua vez, a ausência de estudos sobre o funcionamento, entraves e fragilidades existentes na Rede de Proteção não são consideradas nessa lei. Atrelado a tal fato, a legislação em vigor ainda apresenta lacunas quanto a suas orientações e nenhuma garantia de financiamento para sua execução, sobretudo diante da Emenda Constitucional n 95, vigente desde o Golpe de 2016, que congela os investimentos nas políticas sociais durante vinte anos.

$\mathrm{O}$ atual contexto de instabilidade política e democrática tende ao direcionamento de um Estado penal. Estabelecer procedimentos de cunho jurídico criminalista, travestidos de proteção integral às instituições públicas voltadas para o atendimento de crianças e adolescentes, traz também implicações aos profissionais que, por força da lei, são responsabilizados pela omissão ou recusa do Estado.

Tais situações são mais recorrentes a profissionais que em sua prática diária atuam junto a esse público. Apontamos neste trabalho como tendências requeridas da profissão do assistente social: a visibilidade de sua prática para além do que está posto, a fim de conseguir resolver as demandas que se apresentam ao Serviço Social; intervenção e documentação produzida dotados de capacidade crítico-dialética inerente ao fazer profissional para além de coleta de relatos ou depoimentos em termo de apuração de fatos comuns ao trabalho policial, ministerial e dos tribunais.

Deve-se salientar que as demandas requeridas nos moldes da escuta especializada sempre existiram. Contudo, a Lei n 13.341/17, além

populares e promoveu, através da ação das elites, a atualização do mecanismo democráticos formais [...]" (Amaral, 2010, p. 60). 
de institucionalizar o depoimento especial, assinala colateralmente a legitimidade das requisições dos órgãos de investigação. É imprescindível entender que faz parte do funcionamento do SGD o compartilhamento de informações relativas ao atendimento das necessidades de crianças e adolescentes e seus familiares, no sentido de que as violações identificadas não reincidam. No entanto, em tais articulações ganha relevo as ações de responsabilização em detrimento das de proteção.

Assim, torna-se imprescindível criar mecanismos de escuta que possibilitem que crianças e adolescentes falem por si, considerando-os como sujeitos de direitos, que vão além das finalidades de produção de provas. Estes não devem ser vítimas de manipulação, mesmo que seja para garantir seu direito a proteção.

\section{Referências}

ABESS. Diretrizes gerais para o Curso de Serviço Social. Cadernos Abess, São Paulo, n. 7, 1997.

AMARAL, Ângela Santana do. A categoria sociedade civil na tradição liberal marxista. In: MOTA. Ana Elizabete (org.). O mito da assistência social: ensaios sobre Estado, política e sociedade. 4. ed. São Paulo: Cortez, 2010.

AZAMBUJA, Maria Regina Fay. A interdisciplinaridade na violência sexual. Serviço Social \& Sociedade, São Paulo n. 115, 2013.

BATISTA, Vera Malaguti. Loic Wacquant e a questão penal no capitalismo neoliberal. Rio de Janeiro: Revan, 2012.

BRASIL, Lei n. 13.431, de 4 de abril de 2017. Brasília: Senado Federal, 2017.

BRASIL. Estatuto da Criança e do Adolescente de 1990. Brasília: Senado Federal, 2008a.

BRASIL. Constituição da República Federativa do Brasil de 1988. Brasília: Senado Federal, 2008b.

CONSELHO FEDERAL DE SERVIÇO SOCIAL. Nota técnica sobre o exercício profissional de assistentes sociais e as exigências para a execução do Depoimento Especial. 46 ENCONTRO DO CONJUNTO CFESS-CRESS. Brasília: CFESS, 2018. 
CONSELHO FEDERAL DE SERVIÇO SOCIAL. Ofício CFESS nº 041/2014 pedido de providências ao presidente do Conselho Nacional de Justiça. Brasília: CFESS, 2014a.

CONSELHO FEDERAL DE SERVIÇO SOCIAL. Atuação de assistentes sociais no sociojurídico: subsídios para reflexão. Brasília: CFESS, 2014b.

CONSELHO FEDERAL DE SERVIÇO SOCIAL. Código de Ética do/a Assistente Social comentado. São Paulo: Cortez, 2012.

CONSELHO FEDERAL DE SERVIÇO SOCIAL. Lei de Regulamentação da Profissão de Assistente Social. Lei 8662, de 7 de junho de 1993.

CONSELHO NACIONAL DOS DIREITOS DA CRIANÇA E DO ADOLESCENTE. Resoluções n 113/117. Brasília: Conanda, 2006.

CURY, Munir (coord.). Estatuto da Criança e do Adolescente comentado: comentários jurídicos e sociais. 9. ed. São Paulo: Malheiros, 2008.

GUERRA, Yolanda. Palestra do painel Ética e Sigilo Profissional. 4 CONGRESSO MINEIRO DE SERVIÇO SOCIAL: 80 anos de Serviço Social tendências e desafios. Belo Horizonte: Cress MG, 2016. Disponível em: https://www.youtube.com/watch?v=rb1QGqVw6A0\&t=357s. Acesso em: 14 out. 2018.

GUERRA, Yolanda. A instrumentalidade do Serviço Social. 10. ed. São Paulo: Cortez, 2014.

GUERRA, Yolanda. A instrumentalidade do assistente social. Cadernos do Curso de Especialização à distância em Políticas Sociais. Brasília: UNB/Abepss/CFESS, 2000.

IAMAMOTO, Marilda Villela. O Serviço Social na cena contemporânea. In: CFESS/ABEPSS. Serviço Social: direitos sociais e competências profissionais. Brasília: CFESS/Abepss, 2009. p. 15-50.

MIOTO, Regina Célia Tamaso; CAMPOS, Marta Silva; CARLOTO, Cássia Maria (orgs.) Familismo: direitos e cidadania contradições da política social. São Paulo: Cortez, 2015.

MOTA, Ana Elizabete (org.). Desenvolvimentismo e construção da hegemonia: crescimento econômico e reprodução da desigualdade. São Paulo: Cortez, 2012.

MOTA, Ana Elizabete. As dimensões da prática profissional. Presença Ética, Recife, v. 3, n. 3, p. 9-14, dez. 2003.

ORTIZ, Fátima Grave. Serviço Social e trabalho interdisciplinar. In: MOTA, Ana Elisabete; AMARAL, Angela. Serviço Social brasileiro nos anos 2000: cenários, pelejas e desafios. Recife: Editora UFPE, 2014.

PRATES, Jane C. A mediação da teoria e do método marxiano na formação profissional. Textos \& Contextos, Porto Alegre, v. 11, n. 1, p. 116-128, jan./jul. 2012. 


\section{Sobre as autoras}

Ana Carolina Galvão - Especialização em Instrumentalidade do Serviço Social.

E-mail: anacarolgalvao@gmail.com

JANAÍNA BARbOSA DE MoRAIS - Especialização em Instrumentalidade do Serviço Social.

E-mail: janabarbos@yahoo.com.br

Nilmar Santos - Programa de Pós-Graduação em Serviço Social.

E-mail: nilmar.servicosocial@hotmail.com 